\title{
REVISÃO CRÍTICA SOBRE A ESTRUTURA AGRÁRIA NA REGIÃO OESTE DE SANTA CATARINA: 1960- 1980
}

\author{
Marcos Rogério Pinto ${ }^{1}$ \\ Claiton Márcio Da Silva
}

\begin{abstract}
RESUMO
O presente estudo procura analisar as concepções do processo fundiário no oeste do estado de Santa Catarina. Diante do projeto de modernização institucionalizado, houve uma caracterização dos espaços e propriedades rurais, buscando não só apenas solucionar a tensão social local, bem como efetivar uma pré-condição ao seu desenvolvimento, estabelecendo uma organização social do Estado nas linhas de fronteira. O Processo de expansão e modernização concentrado na questão fundiária, acarretou em um impacto ambiental, e aprofundamento da deterioração da agricultura nos modelos familiares, intensificando as concepções e práticas de cultivos novos propostos por um modelo caracterizado em uma representação socioeconômica distinta no capital transnacional. Procuro fazer uma revisão crítica literária dos elementos históricos constitutivos desse processo para fundamental compreensão de conflitos sociais e ambientais que se estenderam na formação da fronteira da região sul do oeste de Santa Catarina.
\end{abstract}

Palavras-chave: Regularização Fundiária. Modernização. Tensão Social. Produção agrícola. Faixa de Fronteira.

\begin{abstract}
The present study seeks to analyze the conceptions of the land process in the west of the state of Santa Catarina. Faced with the institutionalized modernization project, there was a characterization of rural spaces and properties, seeking not only to solve the local social tension, but also to make a precondition for its development, establishing a social organization of the State on the frontier lines. The expansion and modernization process focused on the land issue, resulted in an environmental impact, and deepening the deterioration of agriculture in family models, intensifying the conceptions and practices of new crops proposed by a model characterized in a distinct socioeconomic representation in transnational capital. I try to make a critical literary review of the historical elements that make up this process for a fundamental understanding of social and environmental conflicts that extended in the formation of the border of the southern region of western Santa Catarina
\end{abstract}

Key words: Land Tenure Regulation. Modernization. Social Tension. Agricultural Production. Border Band.

Data de submissão: 14.09 .2020

Data de aprovação: 20.10 .2020

\section{INTRODUÇÃO}

O presente estudo procura analisar as concepções do processo fundiário no oeste do estado de Santa Catarina. Diante do projeto de modernização institucionalizado, houve uma caracterização dos espaços e propriedades rurais, buscando não só apenas solucionar a tensão

\footnotetext{
1. Graduação em História (2016), Mestrando em Ciência e Tecnologia Ambiental (2020), Universidade Federal da Fronteira Sul - UFFS/Campus Erechim/Rs. E-mail: marcosrogeriop@ gmail.com

${ }^{2}$ Graduação em História pela Universidade do Oeste de Santa Catarina (1999), Mestrado em História pela Universidade Federal de Santa Catarina (2002) e Doutorado em História das Ciências pela Casa de Oswaldo Cruz (COC/Fiocruz, 2009), com estágio de doutorado (sanduíche) na University of Guelph, Ontário, Canadá, Pós-Doutorado em Science, Technology and Society (STS) no Massachusetts Institute of Technology (MIT) Universidade Federal da Fronteira Sul - UFFS/Campus Chapecó/SC. E-mail: claiton@uffs.edu.br
} 
social local, bem como efetivar uma pré-condição ao seu desenvolvimento, estabelecendo uma organização social do Estado nas linhas de fronteira. O Processo de expansão e modernização concentrado na questão fundiária, acarretou em um impacto ambiental, e aprofundamento da deterioração da agricultura nos modelos familiares, intensificando as concepções e práticas de cultivos novos propostos por um modelo caracterizado em uma representação socioeconômica distinta no capital transnacional. Procuro fazer uma revisão crítica literária dos elementos históricos constitutivos desse processo para fundamental compreensão de conflitos sociais e ambientais que se estenderam na formação da fronteira da região oeste no sul de Santa Catarina.

Das razões que procuro nesse trabalho reunir uma revisão crítica de outros específicos estudos realizados até então sobre os processos de colonização da região oeste catarinense entre no espaço dos anos de 1960 e 1980, onde parto de dois princípios: Uma tentativa de levantar um esboço de um quadro de linhas de pesquisa associadas a esse tema historiográfico, onde poderemos viabilizar nessa tarefa um índice de apontamentos nas pesquisas mais atualizadas produzidas por esses pesquisadores. E num segundo momento, busco revisar nessas pesquisas, onde apontam especificamente para o processo de formação e transformação do modo de vida para sustentar um modelo econômico baseado na produção agroindustrial, onde a mudança da paisagem, os novos comodities, e em conclusão, as alterações no cenário, economicamente e socialmente, são colocadas entre o espaço de tempo proposto.

A questão agrária no Brasil suscitou estudos clássicos nas áreas de história, ciências sociais, bem como em estudos ligados às ciências agrárias, notadamente os estudos voltados ao desenvolvimento. No decurso do século XX, autores como Caio Prado Júnior, Celso Furtado, Ignácio Rangel e Alberto Passos Guimarães, criticaram a herança do latifúndio na formação da sociedade brasileira e buscaram entender formas no que tange as relações econômicas e de organização de trabalho. Após a guerra, os estudos agrários se firmaram a partir de uma perspectiva crítica à injusta concentração de terras nas mãos de um pequeno número de latifúndios, cada vez mais pautados em estudos críticos sobre o avanço das fronteiras agrícolas, a violência nos campos, entre relações sociais e a repressão política.

[...] entendemos que o empreendimento colonizador iniciado na década de 1930 ,
objetivando a integração da região ao estado e à nação disputou e se consolidou
frente à tradição política característica da primeira república - coronéis, fazendeiros
locais, patrimonialismo, e aos grupos sociais hoje chamados de tradicionais -
populações indígenas e caboclas. Tal consolidação ficou evidenciada no controle
social exercido pela atuação do estado em aliança com a igreja e as companhias
colonizadoras [...] (SILVA, 2017, p. 32).

A estrutura agrária de um país, bem como uma relação de distribuição organizacional política e equidosa, pressupõe passar por uma intervenção intrínseca do Estado, buscando entre mudanças naturais e impostas economicamente e socialmente proporcionar corrigir e adequar a ocupação dos indivíduos nesses espaços.

\section{FUNDAMENTAÇÃO TEÓRICA}

O Brasil tem em seu histórico uma continuidade de conflitos e desdobramentos ligados ao ambiente rural e concentrado principalmente na questão de posse. Diante desse tema, vários autores proporcionaram estudos em questões de problemas ambientais, territórios de ocupação indígenas e quilombolas, disputas de movimentos sociais e grandes proprietários. Os conflitos entre as organizações camponesas, as lideranças da Igreja católica, e partidos políticos foram visitados pelo trabalho do autor José de Souza Martins (MARTINS, 1981), onde esse busca uma compreensão das disputas desses grupos no conceito da reforma agrária. 
Os autores Carlos Teixeira Silva e Maria Yedda Linhares (TEIXEIRA, LINHARES 1981), publicaram trabalhos quanto aos debates políticos econômicos e agrários e o processo de industrialização, estabelecendo a relação com os clássicos de Caio Prado Junior e Alberto Passos Guimarães. E por fim, a preocupação do tema também foi resgatada mais adiante nos trabalhos de Angela Kageyama (KAGEYAMA, 1993), onde essa ressalta as abordagens dos clássicos quantos aos aspectos sociais da vida dessas populações que "vivem do campo".

O problema dissimulado quanto a questão agrária ratifica o estudo aprofundado de discussões que permeiam nossa sociedade suscetivelmente anos após anos, seguidos de impasses. No recorte histórico final, procuro tomar como referência os autores com trabalhos atuais que debruçaram sobre essas fontes, contextualizando para este a questão agrária no Oeste Catarinense.

Nos trabalhos apresentados em História da Fronteira Sul, elaborados com proposito de percorrer um campo da historiografia regional evidenciando acerca de fontes históricas em muito ignoradas sobre a colonização da região oeste ${ }^{3}$, aponta-nos a compreender as representações que foram produzidas no processo histórico da colonização. O livro nos traz uma coletânea com 16 textos onde os conceitos políticos, geográficos, culturais e a memória desses ambientes são transformados e disputados pelos agentes desse registro histórico, como mencionado em:

A história da região pode ser entendida como um caso de guerra de histórias, e o resultado dessa disputa influência diretamente na interpretação sobre a formação social do território e, também, pode ter implicações na elaboração nas políticas públicas para a região (ZARTH, 2015, p.11).

A temática desses estudos apresentava uma carência de registros mais profundados onde os pesquisadores abordaram paulatinamente conceitos ignorados nos registros de fontes despercebidas nessa disputa histórica, atribuindo uma complexidade nas construções do que se determina uma região Fronteira Sul, onde delimita-se o Oeste Catarinense.

Cada texto em seus capítulos atenta nos ressignificados na história, trabalhando de forma completa um estudo multidisciplinar, diante da região, "As fronteiras e os países não estiveram sempre onde estão, bem como não existiram sempre. Ambos não são mais que construções da história humana, resultado e expressão de processos sociais. (HEINSFELD, 2015, p.30)"

$\mathrm{O}$ aspecto possivelmente com maior enredamento na formação posterior a colonização, tem apontado nos textos como a ação das empresas colonizadoras, que modificaram totalmente as relações de ocupação do homem e o meio ambiente em todos aspectos. Com vemos em:

Temos a modernização da agropecuária nas décadas de 1960-1980, que intensificou radicalmente os processos mais antigos de intervenção sobre o ambiente como a pecuária e a indústria madeireira e criou novos tipos de problemas ambientais, como a poluição por agroquímicos (SILVA, C. BRANDT, M. CARVALHO, M, p. 27).

Os autores também atentam para esse cenário de mudanças principalmente após os anos de 1950/60 como se segue:

...contexto de industrialização, é cada vez mais evidente a necessidade de sincronia entre campo e cidade, intensificando a produção agrícola através de técnicas e tecnologias consideradas modernas e, por consequência, liberando a mão de obra

\footnotetext{
${ }^{1}$ Ainda que seja inadequado falar em identidade regional no singular, pois a população da região participa de ambientes culturais bastante distintos, é possível perceber algumas características comuns no processo de formação do espaço da Mesorregião Grande Fronteira do Mercosul. ZARTH, Paulo A.
} 
excedente para as atividades urbano-industriais. O processo iniciado na década de 1950 alcança um grau de complexidade já na década de 1970, momento em que a região Oeste passa a ser considerada o "celeiro catarinense". (SILVA, C. BRANDT, M. CARVALHO, M, p. 272/288).

Nos registros históricos regionais se fazem presente muitas vezes uma retratação de uma colonização de progresso, de um momento divisor de uma fundação da estrutura da região como apresenta-nos:

\begin{abstract}
A história dos municípios originados do processo de colonização produziram a ideia de que tudo começou com a fundação das colônias, numa espécie de mito fundador. As histórias locais, geralmente, se dividem entre antes e depois da colonização. Ainda que os povos indígenas e caboclos sejam mencionados, a fundação das colônias sempre aparece como ponto de inflexão na história e associada à ideologia do progresso e do pioneirismo. (ZARTH, 2015. p. 14).
\end{abstract}

A pesquisa apresentada nas linhas de História da Fronteira Sul nos faz observar com clareza as demarcações que são apontadas nos registros históricos ignorados, muitas vezes por detrimento das disputas de uma memória empurrada por uma cultura de progresso, indígenas e caboclos são ocultados nos registros para uma determinada cultura histórica dominante.

De certa forma, a preocupação com a questão agrária no Oeste de Santa Catarina surgiu nos anos 1980, mais especificamente no contexto da redemocratização. Desta forma, tenho por objetivo revisar criticamente a bibliografia sobre a questão agrária nacional e local, como forma de disponibilizar um "ponto de partida" crítico para as discussões subsequentes. Busco um diálogo que venha nos trazer a possibilidade de uma pesquisa voltada para interdisciplinaridade entre variadas áreas das ciências ambientais e humanas, em uma reunião das principais discussões, e fatores epistemológicos presentes nessas produções mais atuais, historicizando esses questionamentos na estrutura agrária da região oeste de Santa Catarina.

\title{
2 DESENVOLVIMENTO
}

\subsection{UM OLHAR DOS CLÁSSICOS E OS CONFLITOS QUANTO A QUESTÃO AGRÁRIA}

Caio Prado Junior, intelectual brasileiro que propôs e consolidou seu pensamento nos processos de conhecimento da realidade brasileira, distinguindo-se dos seus contemporâneos marxistas. Buscou no materialismo histórico além dos conhecimentos adquiridos em sua formação em Geografia e Filosofia pela USP, uma metodologia não-dogmática, conferindolhe uma visão crítica e uma ferramenta de concepções sobre dominância até então pouco consolidadas em outras obras brasileiras. Foi militante do Partido Comunista Brasileiro, exercendo crítica em toda sua trajetória política e intelectual direta por meio de produção de seus trabalhos.

A questão agrária para Caio Prado Júnior seguia uma concepção tal, como podemos ver onde esse afirma que não se trata de uma escolha de transição entre a Colônia e a Nação, mas, uma complexa relação dos momentos da evolução histórica brasileira, que o mesmo identifica como período "decisivo", por se constituir, ao mesmo tempo, "uma síntese" dos três séculos de colonização e a "chave preciosa e insubstituível para se acompanhar e interpretar o processo histórico posterior e a resultante dele que é o Brasil de hoje" (PRADO JÚNIOR, 1972, p.9), como aponta no seguinte:

Completam-se assim os três elementos constitutivos da organização agrária do Brasil Colonial: a grande propriedade, a monocultura e o trabalho escravo. Estes três 
elementos se conjugam num sistema típico, a "grande exploração rural", isto é, a reunião numa mesma unidade produtora de grande número de indivíduos, é isto que constitui a célula da economia brasileira (PRADO JR. 1976, p.122-123).

Predomina na análise de deus trabalhos uma visão de que o Brasil partia de uma herança de uma forma de feudalismo que transcendia o presente até então, que o curso de desenvolvimento da sociedade brasileira herdara resquícios enraizados nos modos perante a economia e cultura. Em sua obra A questão Agrária no Brasil, sua perspectiva analítica atribui a uma matriz europeia que exerce uma autoridade na orientação política e social na realidade brasileira, como segue:

\footnotetext{
Essa nova e tão mais complexa estrutura social brasileira, apesar das consideráveis diferenças que a separam do passado, não logrou superar inteiramente esse passado, e ainda assenta, em última instância, nos velhos quadros econômicos da colônia, com seu elemento fundamental que essencialmente persiste, e que vem a ser a obsoleta forma de utilização da terra e organização agrária que daí resulta (PRADOR JR, 1979, p. 49).
}

Para o autor, as práticas das funções do brasileiro no campo remetiam a um aspecto do passado, onde buscava em seus estudos afirmar que o período colonial ainda havia de estar sendo superado em processos e métodos desde a mão de obra a forma de concentração da propriedade de terra. A perspectiva de Caio Prado Junior trás para seus estudos um enquadramento de todo um processo que se estende desde a colonização, em uma constatação quase de passividade na contribuição dos sujeitos e suas complexidades na formação da sociedade agraria brasileira, submetendo o contexto rural ao urbano no processo de avanço dos anos.

Ao autor Alberto Passos Guimarães, foi um intelectual que em seus trabalhos Quatro Séculos de Latifúndio (1963), e A crise agrária (1978) incide nas questões aqui estudadas. Natural de Alagoas, intelectual que partilhou das reflexões quanto a relação da ocupação do homem do campo, e as diretrizes que se estabeleciam dessa entre o Estado, recorria aos desenvolvimentos de pensamentos teóricos na reforma agrária e sua ligação de características com o feudalismo, entre essas projeta:

Durante 388 anos, o latifúndio colonial e feudal e seu semelhante, o sistema escravista de plantação, lançaram mão dos mais variados meios a seu alcance para impedir que as massas humanas oprimidas, que vegetavam a ourela das sesmarias ou se agregavam aos engenhos e fazendas, tivessem acesso à terra e nela fixassem em caráter permanente suas pequenas ou médias explorações. Quando aqui e ali fizeram, longe do núcleo principal das plantações e a seu derredor, eram, mais cedo ou mais tarde, expulsas coma dilatação dos cultivos ou das criações dos grandes senhores (GUIMARÃES, 2009, p. 45).

Para o ensaísta Alberto P. Guimarães, observamos em vários momentos de suas reflexões uma aproximação ao conceito de feudalidade-prussiano, vindo de Lênin, objeto de estudo e pesquisa na obra do autor. No trabalho quanto a Revolução Agrária de Raimundo Santos quanto a Alberto P. Guimarães onde podemos ter esses pontos trabalhados:

[...] já tínhamos registrado a presença da hipótese prussiana em outros intelectuais da geração de Ivan Ribeiro que, como este, buscam conferir alcance estratégico à política de resistência democrática ao regime de 1964. Eles tentam assentar esta valorização da democracia representativa em uma nova visão da nossa modernização (ver, por exemplo, Konder, 1980; Vianna, 1976, especialmente 1981). Quanto ao conceito de feudalismo, então observávamos que o seu uso tinha em Sodré e em Passos Guimarães um sentido instrumental. Em tal acepção - de 
"residualidade feudalista" contemporânea -, esta noção segundo a fórmula leniniana também adquire relevância no comunismo brasileiro. (SANTOS, 2008, p. 34).

Os autores que buscavam nesses conceitos um sentido em compreender todo contexto do mundo agrário. Defrontavam com "ver outras dimensões na imagem de Brasil que possuíam (SANTOS, p. 35). Alberto P. Guimarães, identificava no processo de modernização, uma possibilidade de revelar o uma política conservadora, sugerindo um reformismo democrático de frente única permanente, direção à qual os comunistas já vinham caminhando. (SANTOS, p. 35).

O pensamento do autor se perpassa principalmente na preposição de que o passado colonial exercia relação com a estrutura fundiária. Suas reflexões procuravam e propagavam uma ruptura, como vemos em:

Suas ideias sobre o "período intermediário" e a sucessão das etapas diziam muito do sentido progressivo da nova política: "Assim como no curso da primeira etapa poderá haver fases táticas diversas, como modificações de grau na composição dos governos de caráter nacional e democrático que nos aproximarão do último limite da revolução burguesa, assim também no curso da segunda etapa poderá haver fases táticas diversas e sucessivas nas modificações diversas na composição do governo, à medida que fosse crescendo o peso específico dos operários e seus aliados naturais e particularmente no seio das forças anti-imperialistas e antifeudais. (SANTOS, p. 47).

Essa posição vê-se afirmar muitas vezes na sua postura de militância no campo da política dos Anos 60. O autor foi personalidade que ocupou importante cargo no PCB, envolvendo-se em projetos que delinearam a organização nas atividades do debate político do partido. No que podemos ver propunham os autores até então mencionados, um protagonismo não só, mas principalmente nas questões econômicas, com condicionantes externos, atribuindo a relações de herança feudais a suas teses e reflexões.

No próximo momento pretendo trabalhar outros autores que também referenciam no que diz respeito entre os anos de guerra e pós guerra.

\subsection{A QUESTÃO AGRÁRIA NO BRASIL EM 1945}

Os autores que nesse momento proponho, são os que buscaram um diálogo sobre as questões quanto ao Governo e os Movimentos Sociais que entre os anos Pós-Guerra e o período do Governo Militar, apontaram "ressaltar que até meados do fim dos anos 1970, os estudos voltados à questão agrária no Brasil eram mais restritos à Economia e Sociologia Rural (DAROSSI, p.2)", apresentaram inúmeros desencontros e disputas políticas, reuniram um registro de informação das transformações que acompanharam o campo e a modernização dos elementos constitutivos da questão agrária.

Por agora pretendo apresentar as ações políticas que autores como José de Souza Martins aponta no regime de propriedade da Terra no Brasil, como cita abaixo:

A propriedade fundiária não se concentra nem se divide sem a mediação do capital. [...] a terra não é, no capitalismo, unicamente um instrumento de produção. Se me limito a ver na chamada estrutura fundiária, na distribuição da terra em propriedades grandes, médias e pequenas, apenas quantidades, mais concentração fundiária, menos concentração, estou vendo o supérfluo, não estou vendo o essencial. Não estou vendo que por trás de diferentes tamanhos de propriedade, de diferentes quantidades, existem situações e relações de qualidades diferentes. A propriedade da terra no capitalismo não é, como parece, apenas um dado, um número, um tamanho. A propriedade da terra é uma relação social (MARTINS, 1980, p. 42). 
Na concepção de Martins, a interpretação de autores como Caio Prado Jr, diminuiu ou ignorou a existência do campesinato no país. Para ele "a exclusão do camponês do pacto político é o fato que cercará o entendimento da sua ação política". (MARTINS, 1983, p. 25.). A questão abarca com um problema social, antes de tudo, deflagrado por uma estrutura com diferentes modos na produção e no trabalho para arrecadação nesse capital.

Martins é possivelmente considerado atualmente um dos maiores sociólogos com trabalho voltado a questão rural. Seus trabalhos publicados entre os anos 70, transcorrem sobre compreender os conflitos de apropriação de terras, as disputas envolvidas dos processos de imigrações, e os processos de expansão do capitalismo no campo. Como expõe Marcia Motta:

Naqueles anos, ainda em plena ditadura, muitos autores buscavam entender o rural e as raízes socioeconômicas da pobreza no campo e da concentração fundiária no país. A criação da Comissão Pastoral da Terra, em 1975, cuja missão era a de identificar as mazelas rurais sofridas pelos camponeses e lhe fornecer apoio, inclusive jurídico nas demandas contra os latifundiários, contava com o engajamento de muitos intelectuais em ascensão, como José de Souza Martins (MOTTA, 2014, p.158).

Entre seus trabalhos Martins retrata os impasses sociais e políticos que acompanham a questão agrária no Brasil, abordando toda dimensão econômica e social integrando as questões quanto a reforma agrária, mesmo em publicações mais atualmente:

O mesmo se pode dizer da questão agrária. O regime de propriedade foi instituído pela Lei de Terras, de 1850, já como parte da estratégia dos grandes fazendeiros de assegurar o controle político sobre a transição do trabalho escravo para o trabalho livre. Esse regime começou a dar significativos sinais de obsolescência cem anos depois, nos anos cinquenta. Mas, o protesto social organizado, contra ele, só ganhou alguma robustez nos anos oitenta, trinta anos depois do problema se manifestar, quando começara a se intensificar a expulsão de trabalhadores residentes das grandes fazendas e sua substituição por trabalhadores assalariados temporários. (MARTINS, 2001, p. 4).

Outro sociólogo e antropólogo que debruçou sua atenção aos estudos do campo, e os modelos econômicos e suas fronteiras, que em sua obra: Capitalismo autoritário $e$ campesinato, Otávio Guilherme Velho, apontou comparativamente os elementos de contraste desse tema, e interpretou suas mudanças orgânicas como podemos observar em:

Nada nos leva a crer que na ausência das revoluções burguesas strictu sensu o feudalismo sobreviveria. A centralização já era um fato, assim como a transformação do capital comercial ele próprio em outras formas de capital e o desenvolvimento de manufaturas e indústrias com o apoio do Estado, especialmente em face de necessidades militares. De certa maneira, podemos considerar essas revoluções não como vitórias do capitalismo sobre o feudalismo, mas como a supremacia dum desenvolvimento capitalista burguês sobre outro, mais próximo organicamente do passado, mas que não se esgotava nele. (VELHO, 2009. p.18).

Nessa passagem pode se associar os elementos que o autor vem retratando em seu percurso histórico, sistematizando o processo de transformação dos modelos econômicos dentro da realidade do campo, para buscar aproximar os elementos constitutivos no campesinato, como segue:

Dentro dessas diferentes regiões [...] indivíduos conhecidos por vezes como caboclos ou caipiras que tentavam reproduzir-se basicamente através de uma agricultura voltada para o autoconsumo, mantendo laços frouxos com o mercado e que, como estereótipo, eram conhecidos por serem preguiçosos e sem ambição, 
apenas interessados na mera sobrevivência, sem estarem dispostos a qualquer esforço suplementar. Muitos desses indivíduos na verdade constituíam uma espécie de "exército agrícola de reserva" para a plantation em seus momentos de expansão cíclica. Muitos outros, no entanto, nunca foram apanhados pela expansão da economia de plantation. (VELHO, 2009. p. 107).

Otávio Velho nos propõe um conceito de leitura do capitalismo como "nos seus traços fundamentais, o mesmo poderia ser dito em geral do que estamos chamando de capitalismo (de dominância) autoritário (VELHO, 2009, p. 38)". Nos estudos apresentados em seu trabalho, o autor busca nesse momento caracterizar o processo de fase de mudança do capitalismo "de acumulação primitiva ou original é muito misturada com a acumulação propriamente capitalista. (VELHO, 2009, p. 38)", revendo vários paradigmas de modelos capitalistas em suas semelhanças e diferenças a outros modelos de forças produtivas.

Como tal, a tese prontifica a um esclarecimento das vinculações caracterizadas burguesas e as forças produtivas, onde nessa inter-relação, manifestam uma dominação política e econômica.

Quanto a Maria Ieda Linhares, seus trabalhos se tornaram alicerce para os apontamentos quanto a questão agrária, economia e desenvolvimento no Brasil. Em seus textos expõe as controvérsias na explicação do desenvolvimento econômico, seu curso e influência na população rural, bem como suas pesquisas resultaram em uma trajetória para defesa do estudo da história rural.

As discussões de sua obra buscavam primordialmente um engajamento ao contexto social, colocando um percurso do desenvolvimento histórico, as controversas crises econômicas em exposição distinguindo e explicando-as, trabalhando em diversas áreas com interdisciplinaridade. $\mathrm{O}$ posicionamento das suas pesquisas quanto as fontes e sua identificação na história agrária, sua busca estendeu por toda uma visão embasada pela proposta dos Annales, "com um forte viés marxista, capaz de extrair dos documentos uma visão impressionante da estrutura fundiária, dos grupos sociais, das formas de organização do trabalho, da mobilidade social e, enfim, da família, da herança e das fortunas. (ESTUDOS HISTÓRICOS; V8, 1995, p. 17)".

Outro apontamento dos estudos da autora cabem a distinção da história agrária como um campo da historiografia com suas próprias características separando-o da história econômica. Partindo dos conceitos de fronteira e região, apontou os variados problemas quanto aos trabalhos unidos entre história e geografia como segue:

No segundo ponto, o recorte geográfico, a situação foi e, acreditamos, permanece diferente. Logo em 1977, quando da elaboração de um primeiro trabalho, sentimos a extrema necessidade da definição das relações entre história econômica tradicional, a história agrária não poderia ser uma história "nacional". ... A extrema necessidade de levantamentos de dados, o caráter maciço e serial das fontes, o aspecto de arquipélago da ocupação e do desenvolvimento da sociedade no país, a sucessão de áreas ocupadas e abandonadas, tudo indicava que uma generalização apressada... Desde então nos afigurava impossível justificar como limites de trabalho as fronteiras atuais do país, e, ademais, o esforço para tal seria necessariamente fadado ao fracasso. (ESTUDOS HISTÓRICOS, V8, 1995, p. 17-18).

Como elucidação propôs alguns pontos que formaram indiscutível relevância as pesquisas na história agrária, em foco objetivando as origens das áreas e seus limites no momento estudado, como vemos em:

Em primeiro lugar, cabia claramente determinar os limites da documentação: sendo a história agrária, tal qual nós a ela nos dedicávamos, um imenso esforço de identificação de novas fontes, homogêneas e, sempre que possível, seriais, a 
definição do recorte espacial do nosso objeto deveria claramente acompanhar a produção dessa documentação. (ESTUDOS HISTÓRICOS, V8, 1995, p. 20).

O Estudos desses lugarejos deveriam ser encontrados pelas relações de identificação da região, sejam: administrativamente, agrupamentos rurais, municipais ou mesmo comunidades. Maria Ieda Linhares, particularmente estabelece os critérios para os elementos da pesquisa.

\subsection{A QUESTÃO AGRÁRIA NO BRASIL DISCUTIDA APÓS ANOS 1960/70}

Dois autores revelam em seus trabalhos explanações quanto a realidade histórica brasileira da sociedade, nessa reunião crítica são as publicações Octávio Ianni e Angela Kageyama que aponto de grande contribuição as leituras dos trabalhos de seus antecessores.

Inicialmente as produções de Angela Kageyama, propõe uma perspectiva onde os debates clássicos, principalmente vindos de Furtado (1972), Guimarães (1977) e Prado Junior (1978), enfatizavam a razões onde a busca de introduzir os modelos capitalistas na agricultura brasileira perpassava por grandes dificuldades diante da estruturação arcaica e com heranças enraizadas coloniais, como dispõe referidamente em dois grupos distintos:

No primeiro grupo podemos inserir Rangel e Alberto Passos, cuja perspectiva comum é a de que configura-se uma questão agrária devido as dificuldades que a implementação do sistema capitalista encontra, suscitadas pela estrutura arcaica da agricultura, herança dos restos feudais da economia colonial. Desse ponto de vista, a superação da questão pressupõe a superação dos obstáculos ao pleno desenvolvimento das forças produtivas capitalistas. (KAGEYAMA, 1993, p.14).

E seguindo, o segundo grupo:

No segundo grupo podemos incluir Caio Prado e Celso Furtado, que compartilham a ideia geral de que os problemas agrários são suscitados pelo próprio desenvolvimento do capitalismo, sendo problemas próprios desse tipo de economia, dentro de cujos marcos deverão ser interpretados e atacados. (KAGEYAMA, 1993, p. 15).

Autora expõe os pontos de convergência e discrepância dos autores, buscando aprofundar as reflexões do debate voltado a população do campo, e a forma empregada de força de trabalho. Os trabalhos são relacionados dentro de suas complexidades, buscando nesses protagonistas da questão agrária uma leitura incisiva as soluções discutidas, e as repercussões integradas destes.

Octavio Ianni, sociólogo que buscou apresentar os debates colocados pelo cenário intelectual e político de seus antecessores, buscando dirigir um estudo que constituía todo percurso dos debates das questões sociais da sociedade brasileira, como a questão agrária desde seu início e posterior aos anos 60, para Ianni:

[...] como sempre, os desenvolvimentos históricos da sociedade brasileira, em conjunto, e de suas regiões em especial, recolocam a questão da criação e recriação das desigualdades. Além das desigualdades entre as classes sociais, entre as raças e etnias, entre os homens e as mulheres, criam e recriam-se as desigualdades regionais. Mas essas desigualdades não se reproduzem nunca em termos do que os governantes federais e as burguesias regionais imaginam ser a dinâmica peculiar, curiosa, exótica do lugar: Nordeste, Piauí, Amazônia, Rio Grande do Sul, São Paulo. O que acontece é que essa dinâmica, que parece local, está sempre governada, altamente determinada, pela dinâmica da produção predominante na sociedade, no conjunto do subsistema econômico brasileiro. (IANNI ,1981 a , p.127). 
Em seus trabalhos Ianni fundamenta muitos dos estudos das desigualdades sociais brasileiras, entre suas questões principalmente em seu trabalho Origens agrárias do Estado Brasileiro, e tratado a dimensão do campo, as tensões, leis, medidas dos governos e circunstâncias ao que compunha a dimensões e fronteiras do campo.

Quanto as relações de trabalho no campo sua fundamentação se propõe aos modelos de materialismo econômico e luta de classes, construindo um diálogo com a história, alcançando os papeis das desigualdades ao longo da história do país, como evidencia em:

Em termos da sociedade brasileira, como um todo, as diversidades e desigualdades regionais constituem as bases do desenvolvimento desigual e combinado que caracteriza a formação social brasileira. Primeiro, uma região não repete a outra. São diversas e muitas as formas de organização do trabalho, os graus de integração à economia de mercado, as articulações nacionais e estrangeiras. Segundo, cada região se articula com a outra, em termos de fluxos de capital, tecnologia e força de trabalho, mercadorias, gentes e idéias. (IANNI, 1984, p. 243).

As consequências na formação do país, atravessaram os séculos, como foram apontadas, mesmo diante de contradições, Ianni (1984, p. 248) afirma que "Sob várias perspectivas, a história do Brasil parece ser a história de um povoamento que não termina." Esses autores detiveram leituras importantes desses momentos, onde formaram a base do conhecimento a ser estudado e referenciado, no entanto Ianni dedica assinalar que a realidade trazida nos estudos anteriores detinha um legado de reflexão eurocêntrica, apontando o processo das alterações absorvidas que apontavam esse paradigma.

Como é demonstrado em:

A realidade social, econômica, política e cultural com a qual se defrontavam intelectuais, escritores, políticos, governantes, profissionais liberais e setores populares não se ajustavam facilmente às ideias e aos conceitos, aos temas e as explicações tomadas emprestadas às pressas de sistemas de pensamentos elaborados em países da Europa. Estava em curso uma fase importante no processo de construção de um pensamento capaz de pensar a realidade nacional. (IANNI, 2004, p.18).

\section{RESULTADOS E DISCUSSÃO}

\subsection{A QUESTÃO AGRÁRIA CONTEMPORÂNEA NO OESTE CATARINENSE}

Discutir a formação do eixo do Oeste Catarinense perpassa por todo processo de construção das relações entre discussões geográficas, sociológicas, antropológicas e sua contextualização histórica. A forma desses estudos entrelaça-se no andamento de entrada dos imigrantes no século XIX, que aceleraram o crescimento demográfico e constituíram movimentos de conflitos socias-demográficos. Como expõe Renk:

Uma região não surge espontaneamente; mas, é construída processualmente, com avanços e recuos, deixando ilhas a serem incorporadas posteriormente. Nos discursos de seus mediadores, isto é, daqueles que falam pela região, aparenta ser homogênea. No entanto, diferentes forças contribuem para que se elabore heterogeneamente, como mosaico. A região (substantivada) pressupõe sempre uma história comum, que será fatalmente uma história entre outras. A invenção de uma tradição comum é o passaporte para a constituição da identidade regional. (RENK, 2008, p.10).

A narrativa de formação da região oeste de Santa Catarina da corpo na constituição dos processos de colonização imigrante como atores-chave, promovendo uma ideia de 
formação das fronteiras da região, ignorando inúmeros elementos constitutivos do espaço em momentos passados principalmente por povos indígenas e caboclos ${ }^{4}$ e também identidades nacionais limítrofes.

O Caboclo juntos dos indígenas, seria no contexto histórico alvo desse trabalho de pesquisa, considerado não apenas como um sujeito vindo de uma espécie simplificada de ideia de miscigenação, mas sim como uma constituição mescla de identidades herdadas de uma construção também social, contribuindo na concepção conjunta em uma identidade, como descreve Poli:

O caboclo sempre teve sua vida à margem de sociedade, servindo de mão-de-obra a fazendeiros, ervateiros e madeireiros. Embora representassem a maioria da população, os caboclos sempre foram despossuídos. Raramente conseguiam obter a propriedade de uma pequena área de terra, para se manterem com suas pequenas roças caboclas [...] conceituar o caboclo, realmente, é uma tarefa difícil. Os autores que definem ou tentam definir, esforçam-se em determinar suas origens étnicas, buscando raças básicas que o formaram. Alguns autores, contentam-se em defini-lo como resultante da miscigenação do branco com o índio. Outros colocam-no como cafuso, mameluco ou mulato. Na realidade, o caboclo do Oeste não é simplesmente originário de cruzamento racial puro, mas do cruzamento de indivíduos já miscigenados. O mais importante é saber que a conceituação de caboclo é muito mais social e econômica do que racial. (POLI, 1995, p. 175).

$\mathrm{Na}$ formação redesenhada pelo Estado, as atividades e ocupações de povos anteriores é perpassada como insignificantes perante ao que se determinava uma sociedade com identidade brasileira. Era então necessário formalizar com elementos civilizados:

[...] do atual Oeste Catarinense, as fronteiras administrativas do Império do Brasil, no século XIX, têm um recorte indefinido entre o Brasil e a Argentina, somente resolvido em 1895. Depois, na República, de leste e a norte, acentua-se o conflito referente aos limites internos entre Paraná e Santa Catarina, apenas clareados em 1916, após sucessivas disputas judiciais. A categoria "Oeste" foi precedida, até as duas primeiras décadas do Século XX, por "serra", termo utilizado para designar tudo o que se situasse na Região Oeste do planalto catarinense. (RENK, 2018. p.11).

O principal movimento feito quanto a angariar uma civilidade que coubesse nos moldes do Estado se estabeleceram pelo trabalho e propriedade de terras para manuseio. A autora Arlene Renk, em seus textos descreve a narrativa por parte "da identidade dos chamados colonos de origem como uma categoria de imigrantes descendentes de europeus distinguindo em oposição aos brasileiros caboclos" (RENK, p. 239). Esse que estariam habituados no que se diziam o "trabalho do campo", o agricultor ou nos moldes chamados pioneiros colonos. "Este é numa categoria polissêmica, constitutiva das identidades camponesa e étnica, construída como referencial das virtudes étnicas em oposição à população brasileira" (RENK, p. 240).

Inicialmente a imigração formou-se principalmente por italianos, sucedidos de poloneses e alemães, a partir de 1870. Esses grupos formaram-se vilarejos, vilas e pequenos municípios economicamente ligados a extração de madeira e extração de erva mate, atividades econômicas mais rentáveis, seguido desde o início da persistência dos troperismos até a região do Rio Grande do Sul.

\footnotetext{
2. O significado de Caboclo, pode ser definido como: "o homem pobre da roça, seja qual for sua etnia, ou pode ser sinônimo de caipira” (MARQUETTI, 215, p. 109). Podendo ser atribuídos aos grupos de sujeitos que ocupavam as terras anteriores historicamente as quais o Estado e as empresas colonizadoras viriam adentrar. Esses, "descendentes da miscigenação entre branco (especialmente portugueses) com negros escravos ou libertos e indígenas, que recebeu nome de luso-brasileiro". (MARQUETTI 2015. p.109).
} 


\begin{abstract}
A disponibilidade de terras de campo nos Campos de Palmas, onde se inseriu o atual Oeste de Santa Catarina, favoreceu o estabelecimento das fazendas de criar. As posses foram estimuladas como consequência da Carta Régia de 1808 e legalizadas com a Lei de Terras (1850). Havia interesse da monarquia e, posteriormente, do Império no povoamento dessa região para a contenção do avanço dos argentinos em território brasileiro. A abundância de erva-mate - espécie arbórea com ocorrência nas florestas ombrófila mista e estacional decidual, características na região - era o principal atrativo para os extrativistas. (RENK, 2018. p.11).
\end{abstract}

No trabalho A Luta da Erva, a autora remete aos conceitos históricos da formação do Oeste Catarinense, na observação constante sobre as disputas narrativas na História do Estado. Prematuramente na formação das fronteiras territoriais, a disputa entre Portugal e Espanha, entre Brasil e Argentina, entre Paraná e Santa Catarina, seguida da Guerra do Contestado, "só onde" por fim, o território foi então apropriado de um intenso processo do que foi tratado como colonização, buscando suprimir indígenas e caboclos, esse denominados em toda região desde o Paraná até Rio Grande do Sul, por todo sudoeste, anteriores a essas fronteiras do então Estado Novo.

As fontes históricas trabalhadas, emancipam disputas historiográficas de enquadramentos políticos administrativos apontados como oficiais na história voltada aos progressismos da região, como podemos ver em RENK, p.7: A região Oeste de Santa Catarina era considerada praticamente "despovoada". Nesse sentido como: Os povos indígenas e caboclos, possuíam um modo de vida diferente, nada voltado a comercialização, e tão pouco para títulos de propriedade, e as autoridades não veriam neles uma ligação com o Estado. A Erva mate já do conhecimento da população cabocla anterior aos colonos estabeleceu uma atividade de renda além da agricultura de subsistência e do comercio de madeira. A produção da erva provocou entrelaçamentos das atividades e saberes quanto ao campo dos saberes caboclos, buscavam muitas vezes desinfamar as práticas que acabam por apoderar-se:

\begin{abstract}
A atividade ervateira (corte e enfardamento em "raídos") envolveu, igualmente, população acostumada à vida sem conforto e aos obstáculos naturais. A figura do caboclo, presente nos relatos das disputas de divisas territoriais entre Paraná e Santa Catarina, é marcante na região por sua história e cultura. Praticava a agricultura de subsistência, criava porcos e galinhas para consumo próprio e possuía hábitos nômades. Não estabelecia relação de apropriação com a terra, tampouco pensava em acumular bens, "fazendo para viver". (RENK, 2018. p.12).
\end{abstract}

O colono por outro caminho detinha uma relação com a terra em uma perspectiva de posse, de bem de território e de gerenciamento, de produção e privado. Contabilizava na mesma uma dádiva de recursos naturais para sua apropriação. Como vemos em:

\footnotetext{
Outro traço comum desses imigrantes é a identidade étnica. Eram, na quase totalidade, descendentes de alemães, italianos e poloneses. Compravam as terras como estratégia de reprodução social camponesa. No discurso dos colonos encontramos alguns marcos fundantes, tais como a figura do herói fundador, o ascetismo justificando a sociodiceia e, eventualmente, a reconversão de trajetória de agricultor em comerciante ou congênere. (RENK, 2018. p.14).
}

A promoção e estabelecimento dos conflitos dessas "culturas da terra" perpassaram por todo processo de imigração e reproduz uma ressonância na sociedade até os momentos atuais.

Como vemos o processo de entrada do Estado na reorganização do espaço no Oeste Catarinense foi catapultado pelo emprego de empresas privadas Colonizadoras, essas que na iniciativa de promoção de trabalho em um modelo de concepção de progresso, de mercado e 
valor, esses que conflitavam com a concepção de vida dos habitantes locais. Um dos fatores que viriam a ser dominantes nessa "reunião de culturas", seria o objeto, ou melhor objetivo da terra, suas formas de relações com os recursos naturais e a razão dessas relações. O que nos leva a um autor que Renk recorre em vários momentos no que consiste ao valor apossado a terra:

\begin{abstract}
Acontece, porém, que o trabalho e a terra nada mais são do que os próprios seres humanos nos quais consistem todas as sociedades, e o ambiente natural no qual elas existem. Incluí-los no mecanismo de mercado significa subordinar a substância da própria sociedade às leis de mercado. [...] O ponto crucial é o seguinte: trabalho, terra e dinheiro são elementos essenciais da indústria. Eles também têm que ser organizados em mercados e, de fato, esses mercados formam uma parte absolutamente vital do sistema econômico. Todavia, o trabalho, a terra e o dinheiro obviamente não são mercadorias. O postulado de que tudo o que é comprado e vendido tem que ser produzido para a venda é enfaticamente irreal no que diz respeito a eles. Em outras palavras, de acordo com a definição empírica de uma mercadoria, eles não são mercadorias. Trabalho é apenas um outro nome para a atividade humana que acompanha a própria vida que, por sua vez, não é produzida para venda mas por razões da vida, não pode ser armazenada ou mobilizada. Terra é apenas outro nome para a natureza, que é produzida pelo homem. [...] A descrição do trabalho, da terra e do dinheiro como mercadorias é inteiramente fictícia. (POLANYI, 1980, p. 83-86).
\end{abstract}

Diante dessa perspectiva as atividades de ambos grupos e modelos sociais inevitavelmente entrariam em conflitos. Ao tratar a terra com a abordagem de mercadoria, a regularização dessa viria como um obstáculo em construção acerca do espaço e os usos dele na história, constituindo processos de "avanços" construindo uma narrativa de posse regida por uma ideia judicial, designando regulamentação obrigatória e administrativa as ocupações dessas áreas, como aos moldes das cartas de doações durante as da Leis das Sesmarias ${ }^{5}$. Essas divisões geopolíticas reverberaram desde âmbitos colono/colonizadora, Estado/Estado, até País/País, como vemos:

Seja qual for a narrativa da história (ou a contra história que narra a região), é inevitável que esta apresente múltiplos planos. Estes planos, no entanto, não se encaixam uns aos outros, obrigatoriamente, na suposta linearidade dos contornos. Vejamos o caso da geopolítica, com seus limites. No caso em questão, do atual Oeste Catarinense, as fronteiras administrativas do Império do Brasil, no século XIX, têm um recorte indefinido entre o Brasil e a Argentina, somente resolvido em 1895. Depois, na República, de leste e a norte, acentua-se o conflito referente aos limites internos entre Paraná e Santa Catarina, apenas clareados em 1916, após sucessivas disputas judiciais. A categoria "Oeste" foi precedida, até as duas primeiras décadas do Século XX, por "serra", termo utilizado para designar tudo o que se situasse na Região Oeste do planalto catarinense. Instituições ali inseridas, como as eclesiásticas, tinham sede fora de seus limites, quando não fora do estado catarinense. Nas primeiras décadas da colonização feita por agricultores oriundos do Rio Grande do Sul (século XX), o atendimento médico, os jornais que circulavam

\footnotetext{
${ }^{3}$ SESMARIAS sam propriamente aquellas que se dam de terras, casas, ou pardieiros, que foram ou sam d'alguũs senhorios, e que já em outro tempo foram lauvradas e aproueitadas, e agora o nom sam, as quaes terras, e os bens assi danificados e destroidos, podem e deuem seer dados de Sesmarias polos Sesmeiros que pera esto forem ordenados, os quaes Sesmeiros a Nós soomente pertence de os dar, e poer nos Lugares onde ouuer terras, onde se as Sesmarias ouuerem de dar, forem foreiras ou tributarias a Nós, ou aa Coroa de Nossos Reynos, quer se os foros e tributos arrecadem pera Nós, quer pera outrem, a que os Tenhamos dados, Acustumamos dar por Sesmeiros os Nossos Almoxarifes dos Luguares, ou Almoxarifados onde, os taees bens, ou terras esteuerem. (Ordenações Manuelinas. p.164. Coimbra: Real Imprensa da Universidade de Coimbra, 1797; reprodução "facsimile”, Lisboa: Fundação Calouste Gulbenkian, 1984).
} 
pelas colônias, o comércio para a banha, entre outros, eram recursos buscados naquele Estado. (RENK, 2018, p.11).

Seria estabelecida em dicotomia a condição de ocupante do espaço da terra no campo, adjetivando uma população (indígena e cabocla) que residiam em terras anteriores a chegada dessas empresas colonizadoras, como vemos em:

Num grupo, os brasileiros, além de não terem 'papéis', tinham outra concepção de terra. Essa era do 'Brasil', do 'Governo', ou de 'Deus' e não havia porque comprála. 'Tinha terra à vontade. Cada um tirava o seu sitiozinho', contam. Os de origem europeia, ao contrário, prezavam os papéis, faziam questão de tê-los. Tinham também outra concepção de terra. Essa era um capital a ser transmitido aos filhos. Era indispensável para serem considerados colonos (RENK, 1999, p. 16).

Nessa construção de narrativas, foram formalizados os "posseiros" ou de forma pejorativa: "intrusos", diante da ausência de documentação territorial, o chamado "Título de Posse" segurado pela Lei de Terras de $1850{ }^{6}$, critério matriz da efetividade de posse da propriedade, geraria o componente de disputas de inúmeras transformações sociais e territoriais.

O processo que corresponde as posses de terras legitimava o proprietário de um documento, esse emitido em cartório, que afirmava o detentor de "dono da terra". O que se demonstrou uma falha legislativa, onde várias famílias e moradores anteriores nem ao menos detinham conhecimento ou condições dessa regularização. Essa iniciativa ainda revelou problemas, onde "ocupantes de terras nativos" eram retirados de suas terras, e outros "colonizadores" aproveitavam a condição para ocupar terras dizendo-se proprietários anteriores a vinda da empresa Colonizadora, designando equívocos na expressão categorizada de "intruso".

Essa iniciativa de declaração de concessão de terras procurava promover uma exploração dos recursos naturais, em suas florestas, para condições econômicas perfazendo uma formação de território e sociedade, buscando solução na criação de municípios e identidades sociais. O Ecossistema dessa floresta possibilita inúmeras riquezas e recursos naturais, mas em primeiro plano busco analisar o fator determinante da relação do homem em sua convivência de exploração especificamente aqui mostrada nas condições de extração de

\footnotetext{
${ }^{4}$ Após a iniciativa organizacional do Estado Brasileiro da LEI DE TERRAS, de $\mathrm{n}^{\circ} 601$ de 18 de setembro de 1850, promulgada por Dom Pedro II:

"Dispõe sobre as terras devolutas no Império e acerca das quais não possuídas por títulos de sesmarias sem preenchimento das condições legais, bem como por simples título de posse mansa e pacífica, e determina que, medidas e demarcadas, as primeiras sejam elas cedidas a título oneroso, assim para empresas particulares, como para o estabelecimento de colônias de nacionais e estrangeiros, autorizando o Governo a promover a colonização estrangeira na forma que se declara." (Preâmbulo da lei 601/1850).

Art. $1^{\circ}$ Ficam prohibidas as acquisições de terras devolutas por outro título que não seja o de compra.

Art. $2^{\circ}$ Os que se apossarem de terras devolutas ou de alheias, e nelas derribarem mattos ou lhes puzerem fogo, serão obrigados a despejo, com perda de bemfeitorias, e de mais soffrerão a pena de dous a seis mesez de prisão e multa de 100 \$, além de satisfação do damno causado. Esta pena, porém, não terá logar nos actos posseiros entre heréos confinantes.

Art. $12^{\circ} \mathrm{O}$ Governo reservará das terras devolutas as que julgas necessárias para a colonização dos indígenas; para a fundação de povoações, abertura de estradas, e quaisquer outras servidões, e assento de estabelecimentos públicos, para a construção naval.

Art. $18^{\circ} \mathrm{O}$ Governo fica autorizado a mandar vir anualmente á custa do Thesouro certo numero de colonos livres para serem empregados, pelo tempo que for marcado, em estabelecimentos agrícolas, ou nos trabalhos dirigidos pela Administração publica, ou na formação de colônias nos logares em que estas mais convierem; tomando antecipadamente as medidas necessárias para que taes colonos achem emprego logo que desembarcarem. Disponível em http://www.planalto.gov.br/ccivil_03/LEIS/LIM/LIM601.htm 30/07/2020.
} 
madeira, fonte principal econômica nos estabelecimentos da ocupação das empresas colonizadoras na região.

E necessário mencionar o conflito da Guerra do Contestado, como possivelmente um os dos movimentos iniciais do Estado quanto a expropriação de terra, buscando raízes que contextualizariam a disputa desse território por sua biodiversidade rica em sua floresta de araucárias $^{7}$.

Durante toda contenda da demarcação dos Estados de Santa Catarina e Paraná reuniase um agrupamento de pessoas sertanejas que em meio interesses de forças governamentais em disputa, despontou um conflito armado entre forças militares e caboclos desalojados de suas terras, como vemos em:

No ano de 1911, ocorreram os primeiros despejos de antigos moradores da região do Contestado, expulsos das proximidades da ferrovia, cujas terras ago-ra pertenciam à Brazil Railway Company (VINHAS DE QUEIROZ, 1977). Era gente que há quase um século povoara estes campos devolutos e de repente foi surpreendida com a notícia da venda ou do arrendamento a terceiros, que, armados do título de propriedade, não tardaram a procurar desalojá-los como intrusos (Jornal A Tribuna Curitiba 05/11/1914). Cabe conferir também que o primeiro ajuntamento de sertanejos na região do Contestado ocorreu em seguida, no ano de 1912. Alguns fatos ocorridos, no ano que antecedeu aquilo, chamam a atenção. Os sertanejos juntaram-se em torno de José Maria, um benzedor e curandeiro que receitava ervas, dava conselhos e exercia práticas anteriormente realizadas pelo velho monge João Maria. Com José Maria, principiou a aglutinação que gerou a Guerra do Contestado iniciada em 1912, estendida até 1916. (HIS. FRON. S, 2016. p.237).

Após o encerramento do conflito afirmou-se as propostas de colonizadoras, que se viabilizaram por meio de novas Leis implantadas em repercussão de concessões feitas nesse momento.

A partir concretização dos processos de burocratização e legislação novos impulsionados pelo crescimento da região no arranque da extração de madeira e construção de ferrovias emparelhadas ao Estado, as empresas colonizadoras configuraram uma ascensão exponencial constituindo um dos fatores fundamentais na voracidade do desaparecimento da araucária, objeto principal dessa economia. O crescimento e transformação populacional exigia maiores demandas, que alavancavam maiores avanços em processo de extração e manuseio de madeira por serrarias, bem como transporte e principalmente espaços para desmatamento como expõem os autores:

\footnotetext{
${ }^{5}$ Esta Floresta, também conhecida como "mata de araucária ou pinheiral", é um tipo de vegetação do planalto meridional, onde ocorria com maior frequência. Esta área é considerada como o seu atual "Climax Climá tico", contudo esta floresta apresenta disjunções florísticas em refúgios situados nas serras do Mar e Mantiqueira, muito embora no passado tenha se expandido bem mais ao norte, porque a família Araucariaceae apresentava dispersão paleogeográfica que sugere ocupação bem diferente da atual. Constataram-se recente mente fósseis (fragmentos de caules) em terrenos dos períodos juracio -cretáceo no Nordeste brasileiro, evidenciando que dentro da "plataforma brasileira" encontravam se coniferales, pois tais fósseis são também encontrados em pontos isolados da borda sul do planalto meridional, como por exemplo em Santa Maria da Boca do Monte, no Estado do Rio Grande do Sul. Como o vulcanismo, iniciado durante o cretáceo e terminado no Terciário Superior, foi o responsável pelo despovoamento vegetal do planalto meridional, a hipótese de que a Araucária angustifolia, atualmente existente neste planalto, penetrou através do "Escudo Atlântico" que se achava unido à grande plataforma afrobrasileira no Paleozóico, parece estar comprovada.

A composição florística deste tipo de vegetação, dominada por gêneros primitivos como Drymis e Araucaria (australásicos) e Podocarpus (afro asiático), sugere, em face da altitude e da latitude do Planalto meridional, uma ocupação referente a partir de refúgios alto montanos. Apresenta quatro Formações distintas: Aluvial, em terraços antigos ao longo dos flúvíos; Submontana, de 50 até mais ou menos $400 \mathrm{~m}$ de altitude; Montana, de 400 até mais ou menos $1000 \mathrm{~m}$ de altitude; Alto montana situada a mais de $1000 \mathrm{~m}$ de altitude. (VELOSO. 1991.p.70)
} 


\begin{abstract}
Dezenas de grupos empresariais se formavam paralelamente a tendência do beneficiamento ou elaboração crescente dos produtos madeireiros. Enquanto a produção madeireira do passado se resumia praticamente a venda de toras in-teiras, ou mais frequentemente tábuas, vigamentos e outras peças de madeira serrada, a partir da década de 1940, passam a se introduzir novos processos técnicos para elaboração de novos produtos madeireiros. Entre estes produtos destacavam-se inicialmente a pasta mecânica, e depois compensados, celulose e papel, que proporcionavam lucros muito maiores aos empresários e com um volume menor de madeira como matéria-prima do que o necessário nas ser-rarias tradicionais (madeira serrada). (HIS. FRON. SUL, 2016. p.271).
\end{abstract}

\title{
4 CONSIDERAÇÕES FINAIS
}

Pretendo apontar nesse trabalho a evolução quanto aos conceitos e concepções quanto a transformação e apropriação do homem e aos espações geográficos no que se vem a se constituir o campo.

Inevitavelmente o impacto dessas atividades na região apresentada aqui alterou consideravelmente sua estrutura, reunido do crescimento e constituição desses assentamentos, as práticas de expansão pecuária e agrícola transformaram todo cenário na contemporaneidade, e posteriormente com surgimento de órgãos regularizadores regido por Leis de propostas de Reformas pelo Estado, essas viriam modificar toda relação do homem e o espaço que ocupou-se nessa região.

Disputas socioeconômicas formam o complexo quadro dessa relação e pode-se apontar que nenhuma solução definitiva e um avanço final está próximo de acontecer. O processo de expansão e modernização concentrado na questão fundiária, acarretou em um impacto ambiental, e esse agravou-se em inúmeros problemas que podem ser facilmente identificados nas proximidades desse campo ou área rural, bem quanto a cidades que predominam o destino dessas populações e recursos gerados.

\section{REFERENCIAS}

BRASIL. Constituição da República Federativa do Brasil, de 5 de outubro de 1988. Diário Oficial da República Federativa do Brasil. Brasília: 5 out. 1988.

BRASIL. Lei n. 581, de 4 de setembro de 1850. Estabelece medidas para a repressão do tráfico de africanos neste Império. ColeçMendonçanão das leis do Império do Brasil, Rio de Janeiro, p. 267, v. 1, parte 1, 1850.

BRASIL. Presidência da República. Metas e bases para a ação do governo. Brasília, 1970.

GERHARDT, Marcos; NODARI, Eunice S; MORETTO, Samira P. Org; História ambiental e migrações: diálogos. São Leopoldo: Oikos; Chapecó: UFFS, 2017.

IANNI, Octávio. Pensamento social no Brasil. Bauru, SP: EDUSC, 2004.

INST. NAC. COLONIZAÇÃO REFORMA AGRÁRIA. Internet; MEDEIROS, L. Reforma agrária; PALMEIRA, M. Estado; SILVA, J. Caindo; VEIGA, J. Reforma.

KAGEYAMA, A. \& BERGAMASCO, S. M. P. P. A estrutura de produção no campo em 1980. Perspectivas, São Paulo, 12/13, pp. 55-72, 1989/90. 
KAGEYAMA, A. A questão agrária brasileira: interpretações clássicas. Revista Reforma Agrária, Campinas, v. 23, n• 3, pp. 5-17, 1993.

KAGEYAMA, A. et al. O novo padrão agrícola brasileiro: do complexo rural aos complexos agroindustriais. In: DELGADO, G. C. et al. (Org.) Agricultura e políticas públicas. Brasília, IPEA, pp. 112-223, 1990. (Série IPEA, n•127)

KAGEYAMA, A. O subemprego agrícola nos anos 90. Campinas, SP: IEIUNICAMP, março 1997. 16 p. (Texto para Discussão, n• 57)

LINHARES, Maria Yedda; DA SILVA, Francisco Carlos Teixeira. História da agricultura brasileira: combates e controvérsias. São Paulo: Brasiliense, 1981.

LUCA, Tania Regina de. Fontes históricas/Carla Bassanezi Pinsky, (organizadora). Cap. Fontes Impressas. História dos nós e por meio dos periódicos. - 2.ed., $1^{a}$ reimpressão. São Paulo: Contexto, 2008.

MACHADO, Paulo Pinheiro. Lideranças do contestado: a formação e atuação das chefias caboclas (1912-1916). Campinas: Editora da Unicamp, 2004.

MARCIO; BRANDT; MORETTO. Transformando a paisagem: uma história ambiental de Chapecó. In: Chapecó 100 anos: histórias plurais. Chapecó: Argos, 2017.

MARQUETTI e SILVA, Cultura cabocla nas Fronteiras do Sul. In: História da Fronteira Sul. Organizadores: José Carlos Radin, Delmir José Valentini e Paulo A. Zarth- Porto Alegre: Letra \& Vida: Chapecó: UFFS, 2015.

MARTINS, José de Souza. A sujeição da renda da terra ao capital e o novo sentido da luta pela Reforma Agrária. Boletim de Geografia Teorética. Rio Claro, 10 (19), 1980, p. 31-47.

MARTINS, José de Souza. Impasses sociais e políticos em relação à reforma agrária e à agricultura familiar no Brasil. "Dilemas e Perspectivas para o Desenvolvimento Regional no Brasil, com ênfase no Agrícola e Rural na Primeira Década do Século XXI”, FAO Organização das Nações Unidas para a Alimentação e a Agricultura, Santiago do Chile, 2001. MOTTA, Márcia Maria Menendes. O rural à lá gauche: campesinato e latifúndio nas interpretações de esquerda (1955-1996). Niterói: Editora da UFF, 2014.

ORDENAÇÕES, Manuelinas. In: Collecção da Legislação Antiga e Moderna do Reino de Portugal - Parte I - Da Legislação Antiga - por resolução de S. Magestade de 02 de setembro de 1786. Coimbra: Real Imprensa da Universidade de Coimbra, 1797; reprodução "facsimile”, Lisboa, Fundação Calouste Gulbenkian, 1984.

POLANYI, Kar. A grande Transformação - As origens da nossa época. Rio de Janeiro: Campus, 1980.

POLI, Jaci. Caboclo: pioneirismo e marginalização. Cadernos do CEOM, Chapecó SC, Porto Alegre: Letra \& Vida: Chapecó: UFFS, 2015.

PRADO JÚNIOR, Caio. A Questão Agrária no Brasil, São Paulo: Brasiliense, 1979. 
RADIN, José, VALENTINI, Delmir José, ZARTH, Paulo A. História da Fronteira Sul. Porto Alegre: Letra \& Vida: Chapecó: UFFS, 2015.

RENK, Arlene. A formação socioeconômica da região Oeste de Santa Catarina - uma narrativa acerca de franjas e retalhos da identidade regional. Cadernos do CEOM. v. 31, n. 49 Território, migração e diversidade.

RENK, Arlene. A luta da erva: um ofício étnico da nação brasileira no oeste catarinense. $2^{\mathrm{a}}$ ed. rev. Chapecó: Argos, 2006.

RENK, Arlene. Horizontes Antropológicos, Porto Alegre, ano 6, n. 14, p. 239-258, nov. 2000 .

RENK, Arlene. Migrações: de Migrações ontem e de hoje. Chapecó: Grifos, 1999.

SILVA, Claiton Marcio da; HASS, Monica. "O Oeste Catarinense não pode parar aquii". Política, agroindústria e uma história do ideal de progresso em Chapecó (1950-1969). Revista Tempo e Argumento, Florianópolis, v. 9, n. 21, p. 338 - 374. maio/ago. 2017.

VELHO, Otavio Guilherme. Capitalismo autoritário e campesinato. Rio de Janeiro: Difel, 1976.

VELOSO, Henrique Pimenta. Classificaçao da vegetaçao brasileira, adaptada a um sistema universal/ Henrique Pimenta Veloso, Antonio Lourenço Rosa Rangel Filho, Jorge Carlos Alves Lima Rio de Janeiro IBGE, Departamento de Recursos Naturais e Estudos Ambientais, 1991.

ZARTH, Paulo. Fronteira Sul: história e historiografia. In: ZARTH, Paulo; RADIN, José Carlos; VALENTINI, Delmir José. História da Fronteira Sul. Chapecó: Letra e Vida, 2015.

ZARTH, Paulo. História do campesinato na fronteira sul. Porto Alegre: Letra e Vida. Chapecó: UFFS. 2012. p. 115-132. 